\title{
A CASE REPORT ON RANULA
}

\author{
Shaila Sidam ${ }^{1}$
}

\section{HOW TO CITE THIS ARTICLE:}

Shaila Sidam. "A Case Report on Ranula". Journal of Evolution of Medical and Dental Sciences 2015; Vol. 4, Issue 73, September 10; Page: 12790-12792, DOI: 10.14260/jemds/2015/1841

\begin{abstract}
An oral ranula arising in the floor of mouth is a retention cyst arising from the sublingual gland as a result of ductal obstruction and fluid retention. Swelling in the floor of mouth pose a challenge to the surgeon because of the tightly knitted structures in it so while operating care should be taken to avoid injury to the vital structures, most notably injury to the lingual nerve, injury to Wharton's duct with the possibility of stenosis leading to obstructive sialadenitis, and ductal laceration causing salivary leakage. This paper highlights a case report of ranula in the undersurface of tongue which was about $2 \mathrm{~cm}$ and has been successfully treated by excision.
\end{abstract}

KEYWORDS: Excision, Ranula, Marsuplization, Tongue.

INTRODUCTION: The cyst of salivary glands mainly includes Mucocoele, Ranula \& Salivary duct cyst. "Ranula" was first reported by Hippocrates \& Celsius ${ }^{[1,2]} \&$ the terminology mainly gets its origin from the Latin term "Rana" which means frogs belly as the swelling resembles the frogs translucent underbelly.[2,3] There are various causative factors that have been attributed to pathogenesis of ranula but the most accepted one is that it is mainly due to the trauma-direct trauma or from surgery to the floor of mouth. ${ }^{[1,3,4]}$ In this there is rupture of the excretory duct resulting in extravasation of mucous in surrounding tissue leading to formation of pseudo cyst.[1-4] As ranula is mainly seen in the floor of the mouth, they pose a challenging situation both clinically \& surgically because this area exhibits vitally knitted structures. Any lesion in this vicinity could lead to its spread to mediastinum creating a medical emergency \& also makes the surgeons treatments modalities more challenging. Hence here we present a case report of ranula in left undersurface of tongue.

CASE REPORT: A 27 year old Female patient reported to the outpatient department with a chief complaint of painless swelling over the undersurface of the tongue (left) since 3 months. History revealed that the swelling has gradually increased in size to the present size. No history of any pain was reported. There was no previous history of trauma or any history of any procedure done in oral cavity. On examination, a $2 \times 2 \mathrm{~cm}$ bluish fluctuant swelling was seen over the left undersurface of tongue. The swelling was non-tender, soft in consistency and no discharge was elicited. On correlating the clinical findings, the case was provisionally diagnosed as "ranula". After other routine preoperative investigations, excision of ranula was done. Sutures were placed. Patient was kept under observation. The patient was followed up every week for any post-operative complication. 


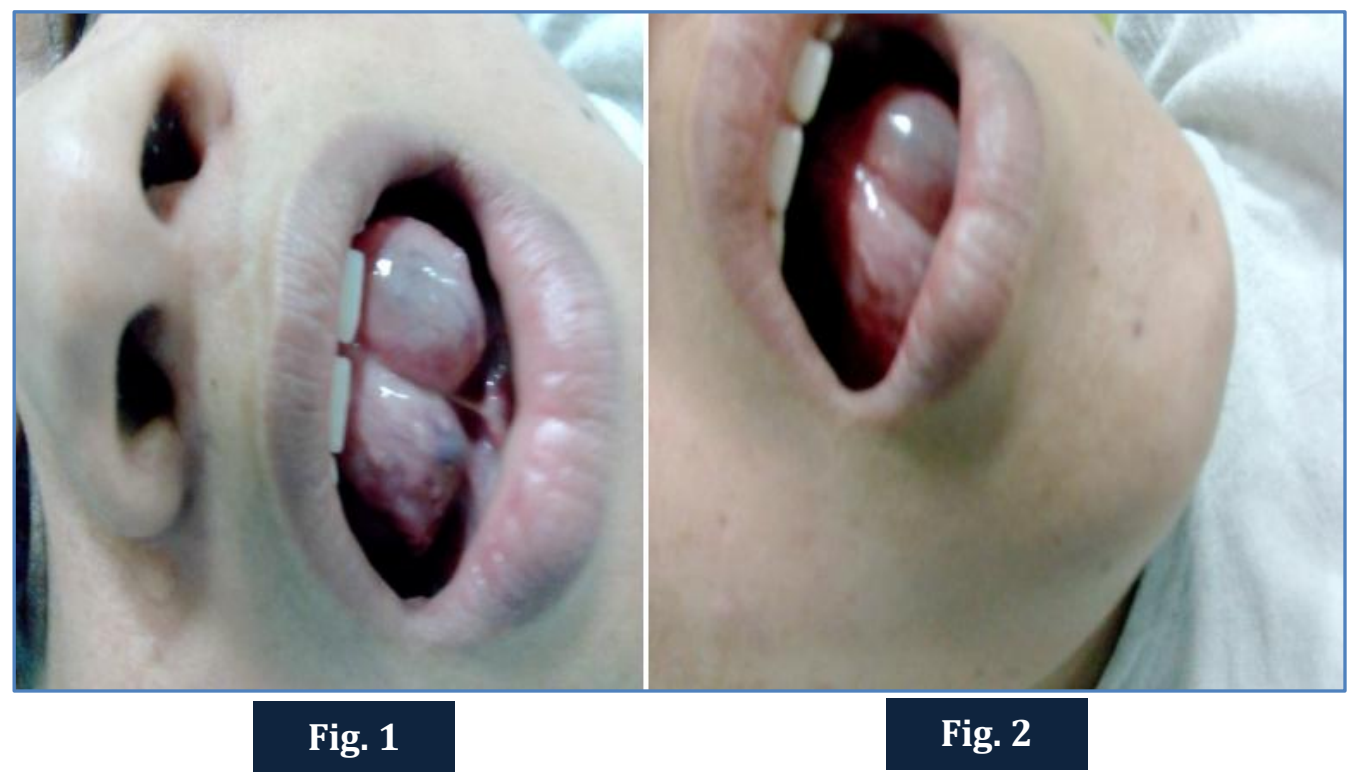

DISCUSSION: Ranula occurs because of rupture of the excretory duct resulting in extravasation of mucous in surrounding tissue leading to formation of pseudo cyst. It usually presents as a well circumscribed, soft, bluish cyst covered by a thin layer of epithelium. The causes of ranula formation are said to be trauma or surgery to the floor of the mouth, or in neck region which may lead to rupture of the sub lingual gland acini or cause obstruction of the sublingual gland duct. Ranula can be classified into two groups, simple (Intra oral) and the plunging (Cervical) type. Simple ranula is much more common than plunging type. A simple ranula is seen as a localized collection of mucous within the floor of the mouth. In plunging ranula, the mucous collection is in the sub mandibular and sub mental space of the neck with 8 or without an associated intraoral collection.

The diagnosis of ranula can be made on the clinical examination and sometimes on computerized tomographic or magnetic resonance imaging findings for the plunging lesion. If there is a doubt about the diagnosis, then you can aspirate the mucous from the lesion and a laboratory determination of amylase content should make the diagnosis of ranula. The differential diagnosis of ranula includes abscess, dermoid cyst, and vascular lesions. There are several different methods of treatment for ranulas, like excision of the ranula via an intraoral or cervical approach, marsupialization, intra oral excision of the sublingual gland and drainage of the lesion, and excision of the lesion with sublingual gland. They usually occur over the floor of the mouth but in this case it occurred over the undersurface of tongue.

\section{REFERENCES:}

1. Dr. Suman Jaishankar, Dr. Manimaran, Dr. Kannan, Dr. Christeffi Magel. Ranula- A case report. JIADS. 2010; 1(3):52.

2. B Godhi, N Agarwal, P Verma, S Kumar Oral Ranula: An insight into pediatric dentistry. Internet scientific publication 2013; 1(11):1-5.

3. Neville, Damm, Allen, Bouquot. Oral \& Maxillofacial Pathology. 2nd edition.2009.

4. Bardhan A, Dev PK, Banerjee S, Islam S. Plunging Ranula (Right Side): A case report. Medicine Today 2013; 25(1): 52-53. 


\section{CASE REPORT}

\section{AUTHORS:}

1. Shaila Sidam

\section{PARTICULARS OF CONTRIBUTORS:}

1. Assistant Professor, Department of ENT, Gajra Raja Medical College, Gwalior.

FINANCIAL OR OTHER

COMPETING INTERESTS: None
NAME ADDRESS EMAIL ID OF THE CORRESPONDING AUTHOR:

Dr. Shaila Sidam,

Room No. 36,

Senior Girls Hostel,

GRMC, Gwalior.

E-mail: gujulsidam@yahoo.co.in

Date of Submission: 22/08/2015.

Date of Peer Review: 25/08/2015.

Date of Acceptance: 03/09/2015.

Date of Publishing: 10/09/2015. 